\title{
Realidad y ficción en un mundo desacralizado. Estudio de La vida breve de J.C. Onetti desde una perspectiva hermenéutica*
}

\author{
Alejandra Sánchez Kornfeld **
}

\begin{abstract}
Resumen
A partir del estudio hermenéutico de la novela La vida breve (1950) de J.C. Onetti, se desprende cómo un individuo sensible a los cambios sociales, intenta desesperadamente adaptarse a una sociedad progresista y mecanizada, donde se ha perdido la noción de trascendencia y pertenencia social. De esta forma, el narrador de esta novela intenta sustentarse ontológicamente a partir del relato de su inconsciente, lo cual sumerge al lector en diferentes mundos creados unos sobre otros que lo alejan cada vez más de la realidad, ahora arrebatada por un espiral cuya fuerza centrípeta aleja el lenguaje de su referente inmediato.
\end{abstract}

Palabras clave: hermenéutica, novela hispanoamericana, existencialismo, metarrelato.

\section{Reality and Fiction in a Demystified World. Study of J.C. Onetti's La vida breve from an Hermeneutical Perspective.}

\begin{abstract}
The hermeneutical study of the novel La vida breve (1950) by J.C. Onetti shows how an individual, sensitive to social change, desperately tries to adapt to a progressive and mechanized society that has lost its sense of social belonging and transcendence. By doing this, the narrator of the novel attempts to sustain himself ontologically on the account of his unconscious which immerses the reader into different worlds created upon each other that take him further away from reality, now captivated by a spiral whose centripetal force distances language from its immediate referent.
\end{abstract}

Key words: hermeneutics, latin american novel, existentialism, metanarrative.

Recibido: 23-10-2012 Aceptado: 25-07-2013

\footnotetext{
* Trabajo realizado para el curso Hermenéutica del texto dictado por el profesor Francisco Aguilera Gajardo.

** Chilena, Magíster en Literatura, Universidad de Chile, Santiago, Chile, alesanchezk@gmail.com
} 
Abordar un texto desde la perspectiva hermenéutica implica entender la interacción lector - obra como "la correlatividad de dos factores y su mutuo condicionamiento en el acto de comprender y explicar" (Schökel, 1994: 66). La circularidad de este fenómeno radica en el acto de comprender el todo desde lo individual y lo individual desde el todo, donde el lector anticipa un sentido que hace referencia a la totalidad del texto y lo va confrontando con el mismo, corrigiendo y enriqueciendo el sentido presupuesto. Esta corrección se lleva a cabo a través de la verificación de la congruencia de cada detalle con el todo, estableciéndose que cuando no hay congruencia, la comprensión ha sido errada. Por esto se dice que la tarea hermenéutica es la de "ampliar la unidad del sentido en círculos concéntricos" (Gadamer, 1977: 361).

El primero de estos círculos es el histórico, donde tras la realización de un pacto de lectura ${ }^{1}$ entre autor y lector real, ambos se transforman en entes liminares que forman parte de un sistema de comunicación concreta. Es dentro de este círculo, el cual corresponde a la realidad concreta de la experiencia natural, donde se describe el contexto de producción de la obra, se analiza su dispositio, los intertextos que en ella se presenten, a la vez que se determina la fábula y las secuencias narrativas, todo lo cual nos permite tanto la apertura de horizontes, como el establecimiento de un macrotexto.

A los efectos de ingresar así en esta dinámica circular del proceso de interpretación, en donde se comprende la parte por el todo y el todo por la parte, comenzaremos por la contextualización de la novela, como parte de un momento histórico concreto. Su autor, Juan Carlos Onetti, nació en Montevideo el año 1909 y falleció en Madrid en 1994. Su novela, La vida breve, fue publicada por primera vez el año 1950 por la editorial Sudamericana. Esta fecha corresponde al advenimiento de las grandes ciudades hispanoamericanas, que desde 1930 comenzaron una fuerte industrialización y para la fecha de la publicación ya habían adoptado el modelo económico capitalista. Es justamente el período de entrada de la región del Río de la Plata a la vida moderna, urbana y basada en una cultura de mercado, donde el estilo de vida y la moral de los ciudadanos

1 Se entiende como pacto de lectura la situación en la cual lector y autor clausuran la capacidad demostrativa del lenguaje, para formalizar así una comunicación condicionada por esta nueva postura lógica. 
cambia radicalmente. El trabajo se tornó mecánico y apuntando a la ecuación capitalista: mayor producción a menor costo, con lo que el arte y la artesanía fueron reemplazadas por la fabricación masiva de productos para el gusto de las masas. Asimismo, como resultado de este trabajo industrializado y de producción en serie, la sociedad se constituyó en capas sociales bien delimitadas y diferenciadas por sus roles laborales, creándose luego una pequeña burguesía que luchaba constantemente por acceder a mayores beneficios económicos y así salir de aquella vida oprimida y anónima a la cual pertenecían. Los aspectos socio-culturales recién mencionados, resultaron en un cambio ideológico y artístico, conformándose así una generación de artistas rioplatenses caracterizada por ser levemente nihilista, que presentaba personajes amorales y desencantados de la sociedad y el mundo.

Entonces, desde una lectura hermenéutica, a partir de esta breve contextualización, se nos abre tanto el horizonte histórico (situaciones que rodean la producción del texto) como el de expectativa (situaciones que rodean la recepción), en cuanto ahora nos enfrentamos al texto como un contenido condicionado y determinado por una totalidad de sentido, totalidad que a su vez "posibilita y condiciona la nueva comprensión de sentido" (Schökel, 1994: 72). En resumidas cuentas, toda situación comprensiva implica una apertura de horizontes, en cuanto siempre es acompañada por saberes previos, pero que no son precisamente el "hecho sobre el que se realiza el acto de comprensión" (Schökel, 1994: 72). Es importante mencionar que para la teoría hermenéutica, la comprensión de un texto radica en la fusión de horizontes, fusión que "tiene lugar constantemente en el dominio de la tradición; pues en ella lo viejo y lo nuevo crecen siempre juntos hacia una validez llena de vida, sin que lo uno ni lo otro lleguen a destacarse explícitamente por sí mismos (Gadamer, 1977: 377). Es decir, no se espera del lector que se enajene y entre en una conciencia pasada (horizonte histórico), sino más bien la proyección de este horizonte se articula como una fase de la comprensión, donde la meta es recuperar esta conciencia pasada desde el propio horizonte presente del lector. Es la creación de lo que Schökel (1994) llama horizonte común.

Ahora bien, entrando un poco más en la novela, su disposición también nos ayuda a situarnos frente a ella, acotando así un poco más la perspectiva frente a la cual ésta se abordará. Desde luego, lo primero que capta nuestra atención es su título: La vida breve, el cual alude al 
aforismo griego traducido por Séneca: "Ars longa, vita brevis"2. Esta sentencia pronunciada originalmente por Hipócrates, corresponde a las dos primeras frases de un aforismo más largo y que alude al arte de la medicina como una labor muy compleja, donde el médico no sólo debía ver lo que era bueno para él, sino también para su paciente, siendo entonces un arte que llevaba toda una vida dominar. Sin embargo, a lo largo de los años, estas dos frases se han descontextualizado y sustentado por sí mismas, entendiéndoseles como la brevedad de la vida frente a la durabilidad y permanencia del arte. En lo que respecta a la novela, tomemos esta última interpretación, la cual se asocia inmediatamente con la obsesión del protagonista de escapar de una realidad intolerable a través de la ficción: "estaría salvado si empezaba a escribir el argumento para Stein, si terminaba dos páginas [...] o tal vez la salvación bajaría del retrato que se había hecho Gertrudis en Montevideo, tantos años antes, colgado ahora en la pared..." (Onetti, 1968: 32-33). Entonces, a través del arte, Brausen, el protagonista, podría abandonar espacial y temporalmente su desesperada existencia, en cuanto sería capaz tanto de transportarse a su idílica Santa María como de retroceder en el tiempo hacia su juventud y la de Gertrudis, evento retratado con el cuadro colgado de la pared ${ }^{3}$.

Nos situamos entonces frente a una vida que, reconociendo su futilidad, se intenta escapar de ella a través del arte. Sin embargo, ¿a qué se debe esta sensación de pequeñez de la vida? Considero que la mejor manera de comenzar a entenderlo es a través del análisis del epígrafe, correspondiente a un extracto de "A song of joys", poema original de Walt Whitman. En este último, el poeta exhorta al lector a vivir una vida exaltada, libre y alejada de la moral piadosa característica del mundo cristiano. Así, cuando Whitman nos dice "Something far away from a puny and pious life", al conjugar los adjetivos puny (endeble) y pious (piadosa) frente al sustantivo life (vida), nos deja en claro que la vida se debilita frente a una moral piadosa, mientras que se fortalece cuando

2 "El arte persistente, la vida breve".

3 Esta idea de salvación a través del arte se ve reforzada por la intertextualidad presente con la obra de Oscar Wilde, El retrato de Dorian Gray. Esto, partiendo del hecho de que el protagonista ficticio del argumento de Brausen se llama Dr. Díaz Grey y corresponde al medio por el cual Brausen se escapa del inevitable avance del tiempo, igual como lo hace Dorian Gray con su retrato. Asimismo, la degradación moral que Dorian sufre luego de retratado, también es sufrida por Brausen después de comenzada su narración imaginaria.

4 "Canto de alegrías".

5 "Algo alejado de la vida endeble y piadosa". 
es "Something escaped from the anchorage and driving free"6". Es decir, en esta novela, la vida alegre será identificada con la libertad, el trance y lo pernicioso, mientras que la moralidad y el control que ella ejerce sobre los hombres, sería una forma de debilitar las vivencias diarias y empequeñecer la vida. Además, es importante mencionar que el poema de Whitman, en su totalidad, está dedicado a la alabanza de aquellos trabajos que dignifican al hombre, a la vez que lo ayudan a relacionarse con su comunidad y con el entorno natural en que vive. Por esto, el hablante lírico rescata aquellas profesiones que se desarrollan al aire libre y que están lejos del trabajo rutinario y alienante de las ciudades modernas. En suma, la libertad a la cual apelan estos versos rescatados en el epígrafe, apunta tanto a la supresión moral como a la superación de una vida moderna que oprime y enajena al individuo.

Más aún, en la estructuración de la novela, conformada por dos partes, también se deja entrever esta necesidad de una vida desanclada. Así, la primera parte correspondería al itinerario que Juan María Brausen realiza para asesinar aquella identidad que lo retiene en los confines de una vida empequeñecida por la rutina laboral y sentimental, mientras que el segundo apartado sería el nacimiento de la vida alegre y perniciosa, causada por la enajenación del personaje en dos alteridades paralelas. Este recorrido queda aún más claro al destacar los nombres de ciertos capítulos cruciales para el desarrollo de la obra; quedando al descubierto el siguiente viaje interno ${ }^{7}$ :

Santa Rosa (tormenta) - La salvación - El regreso - Pequeñas muerte y resurrección - Una separación - El nuevo principio.

En otras palabras, Brausen, al sufrir un impacto emocional con la mutilación de su esposa Gertrudis, se descubre solo, hastiado de su empobrecida existencia (la tormenta) e incapaz de emocionarse o empatizar con los demás, revelándosele que su única salvación es la ficcionalización de su propio ser. A partir de ello, crea la historia del Dr. Díaz Grey e interpreta en la vida real a un tal Arce, sujeto despiadado y despreocupado del resto. Es entonces cuando Brausen comienza a disfrutar de la vida, pero no ya como tal, sino como conjugador de dos alteridades proyectadas desde su ego. Así, entretanto el Dr. Díaz Grey 
y Arce llevan una vida convulsiva y ajetreada, Juan María Brausen se recluye cada vez más en la soledad de su departamento, recostado en su cama y chupando pastillas de menta. Mas, en un momento de desesperación, el protagonista intenta recogerse de su dispersión yoica y regresar a Gertrudis, quien luego de recuperarse de su operación, lo había abandonado. Sin embrago, ya es demasiado tarde, no queda nada que recoger, pues "yo, Juan María Brausen y mi vida no eran otra cosa que moldes vacíos, meras representaciones de un viejo significado mantenido con indolencia" (Onetti, 1968: 131), todo lo cual se refuerza con la inacción característica del personaje, cuya única motivación durante los acontecimientos de la novela, es vivir sus vidas ficcionales. Es entonces cuando esta identidad muere y resucitan los nuevos personajes, creándose, desde luego, un nuevo principio.

Tenemos entonces la anteposición de dos estilos de vida: una alegre, identificada con la libertad y la unión con la naturaleza y la comunidad, y otra fútil, que se equipara con la opresión de un trabajo mecanizado que aleja de la comunidad y de uno mismo. Tal como dice Macleod en la novela, al momento de despedir a Brausen "Yo sé que no soy... quiero decir que no me pertenezco. No del todo libre. Yo soy lo que resuelva Nueva York [...] si usted no se olvida de Brausen y se entrega por completo al negocio... es la única manera de trabajar" (Onetti, 1968: 152). Así, en esta descripción de un estilo de vida moderna, podemos encontrar la primera respuesta al empequeñecimiento de la vida, en cuanto es esclavizante y enajenante, en contraste con la vida anterior a la modernidad, que integraba al sujeto a la vez que lo realizaba socialmente. Entendemos así la necesidad de Brausen de salvarse, de escapar de una vida que lo ha obligado a olvidarse de él mismo y que ha sido construida a partir de los otros, "porque cada uno acepta lo que va descubriendo de sí mismo en las miradas de los demás, se va formando en la convivencia, se confunde con lo que suponen los otros y actúa de acuerdo con lo que se espera de ese supuesto inexistente" (Onetti, 1968: 239).

Sin embargo, distamos mucho de encontrar la necesidad de esta salvación si dejamos fuera de este análisis el recurso de la intertextualidad, tan fuertemente utilizado en la novela. El primero que en ella encontramos, es el ya analizado título que, como vimos, comienza a develarnos un primer sentido del texto, tal como lo hace el intertexto con el poema de Whitman. Ahora bien, para continuar esta develación simbólica, es necesario entrar a dilucidar aquellos intertextos 
que se llevan a cabo en el interior de la obra. El primero, corresponde a la canción "La vie est brève", basada en el poema Peu de Chose et Presque $T{ }^{8} p^{8}$ del poeta belga Leon Montanaeken y musicalizada por Teresa del Riego en 1902. Dentro de la novela, dicha canción es puesta en escena por Mami, un personaje decadente que desea revivir sus años de gloria como entretenedora en París. Sin embargo, la canción, tal y como está plasmada, ha sido intencionalmente manipulada con el fin de acentuar su sentido dentro del texto. Así, se unió la primera estrofa de la canción con la segunda del poema, resultando entonces lo siguiente:

La vie est brève

un peu d'amour

un peu de rêve

et puis bonjour.

La vie est brève

un peu d'espoir

un peu de rêve

et puis bonsoir. ${ }^{9}$

Cuando en realidad, si queremos atenernos al poema, el primer párrafo debiese leerse así

La vie este vaine

Un peu d'amour

Un peu de haine ${ }^{10}$.

Finalmente, si hacemos una lectura doble de esta canción, descubriremos que aquello que se intenta dilucidar es el carácter vano de la vida, en cuanto se compone de unos cuantos sentimientos (amor - odio), esperanza, fantasías e ideales, que finalmente se acaban por

8 La traducción sería algo así como "Poca cosa, pero quizás mucho".

9 La vida es breve/ un poco de amor / un poco de ensueño y después buenos días. / La vida es breve / un poco de esperanza / un poco de ensueño / y después buenas tardes.

10 La vida es vana / un poco de amor / un poco de odio. 
transformar la vida en algo vacío. Tal como dice Brausen "se descubre que la vida está hecha, desde hace muchos años, de malentendidos [...] Fuera de esto, nada; de vez en cuando, algunas oportunidades de olvido, algunos placeres, que llegan y pasan envenenados" (Onetti, 1968: 53).

Esta idea de una vida fútil, se entrelaza perfectamente con otro intertexto presente en la obra. Al finalizar la novela, cuando Brausen ha perdido su última esperanza de felicidad al observar a Raquel ${ }^{11}$ embarazada y vieja, descubre un papel en la mesa de su vecina el cual se titula The New Invocation. Ésta corresponde a una modificación efectuada por el autor liminar, de un rezo conocido mundialmente en los años cuarenta, denominado The Great Invocation, el cual invoca a Dios para que ilumine a la humanidad, destierre al mal y restaure el Plan Divino. Sin embargo, la Nueva Invocación creada por el autor liminar, excluye justamente los párrafos en los cuales se pide por la venida de Cristo al mundo y por la exclusión total de lo demoníaco. Así, lo que se resalta en la invocación de la novela es más bien la idea de una vida que se conjuga como parte de un plan mayor: "Let Light and Love and Power restore the Plan on Earth"12"; incluso el protagonista al leer el rezo resalta esta última expresión como válida. Si se observa bien la frase, puede notarse que como requisito para que el Plan Divino se restaure, están la iluminación, el amor y el poder, ninguno de los cuales está presente en la novela ${ }^{13}$, descartándose entonces la posibilidad de un sentido divino que articule la vida humana.

Asimismo, la frase anterior resulta irónica si se la conjuga con la ya comentada canción "La vie est brève" y con la intertextualidad que se presenta con Marcos 15, 34 y Mateo 27, 46 “Dios mío, Dios mío, ¿por qué me has abandonado?" Dicha frase es introducida en la novela por Stein, como parte de una divagación burlesca e intempestiva que toma lugar en un bar. Ahora bien, para entender la relación de esta expresión con el postulado de una vida sinsentido, es preciso contextualizarla dentro del Nuevo Testamento, donde corresponde a las últimas palabras dichas por Jesús antes de morir en la cruz. Lo importante de esta expresión en la

11 Raquel es la hermana menor de Gertrudis, la cual, por su parecido, representa a esta última en sus años de juventud.

12 "Que la luz y el Amor y el Poder restauren el Plan en la Tierra".

13 Recuérdese que Brausen se separa de Gertrudis por su imposibilidad de amarla, sentimiento que demuestra tener suprimido durante toda la obra. Mas bien estamos frente a un personaje que ha reprimido su afectividad. 
Biblia, es tanto recalcar el lado humano de Cristo, como el gran sacrificio efectuado por Dios para redimir al hombre, corresponde a la

reconciliación con Dios para todos aquellos que reconocen en su muerte la prueba más grande del amor de Dios por nosotros. Entonces deponen el miedo a Dios y comprenden que no estamos sometidos a un destino ciego, sino bajo los cuidados del amor de Dios, que nos empuja por un camino de liberación. (Nuevo Testamento, 1989: 158)

Es en la muerte y posterior resurrección de Cristo donde se encuentra el fundamento del cristianismo, la manifestación del Plan que Dios ha trazado para la humanidad. Sin embargo, en la novela esta frase es desacralizada, tanto por el contexto de enunciación -un bar-como por el emisor -un judío ${ }^{14}$-, presentándose así el primer atisbo de ironía frente a la idea de un Cristo redentor. Prosiguiendo con esta burla, Stein continúa su discurso afirmando: "si tu salvación puede esperar, diría que muy probablemente el otro se restregó las manos y murmuró entre las barbas: "Mis designios son insondables, hijo mío" -Se echó a reír- (Onetti, 1968: 176). Bien se podría decir que "el otro" se refiere a Dios Padre, quien, según un hilarante Stein, respondería a las palabras de su hijo agónico diciéndole que tras este sacrificio hay un Plan misterioso. Todo lo cual no deja de ser cierto en el contexto cristiano, más recordando que acá hay una descontextualización y desacralización ${ }^{15}$ de la religión, podría entenderse todo como una pérdida de fe por parte del hombre hacia este Plan Divino de salvación, arrojando por ende a la humanidad a un destino ciego, al ponerse de relieve el hecho de que es imposible que Dios nos salve de la muerte si fue capaz de matar y abandonar a su propio hijo. No nos queda más que aceptar que estamos arrojados a un "mundo loco"16, desprovisto de toda lógica o sentido último; es la creencia en la nada resultante del aniquilamiento de Dios por parte de la sociedad. Además, si reparamos que el capítulo donde se llevan a cabo las divagaciones religiosas de Stein se llama “La Negativa”, podemos decir que así como Pedro negó a Jesús para salvar su condición terrena, así el hombre moderno niega a Dios para perderse en su propia corporalidad.

14 La importancia de otorgarle la autoridad de esta frase a un judío radica en que ellos no consideran que Jesús haya sido verdaderamente el hijo de Dios y salvador de la humanidad.

15 Se le suma a la desacralización por contexto el hecho de que Stein aluda a Dios como "el otro" y además invente una posible respuesta, es decir, pone sus palabras en la boca de Dios. Asimismo, se suma el que el autor liminar escriba la alusión a Dios sin utilizar mayúscula.

16 Frase con que parte la novela y que repite constantemente Queca. 
En resumen, tenemos un hombre que se enfrenta a una vida vaciada de identidad y de sentido, producto de una sociedad que lo enajena. Consecuencia de lo anterior, este último se sumerge en una vida de decadencia, ya sea simulada -al encarnar a Arce-, como virtual con la historia de Díaz Grey-. Decadencias que se van alternando estratégicamente con la historia de Juan María Brausen, alimentándose así unas con otras en un juego de reciprocidad y paralelismo.

Para entender mejor el proceso transformativo del protagonista, es preciso analizar brevemente la arquitectura de la novela, la cual utiliza el procedimiento de engaste o narración encuadernada ${ }^{17}$. La primera de estas narraciones es la historia de Juan María Brausen, publicista uruguayo que reside en la ciudad de Buenos Aires con su esposa Gertrudis, quien recientemente ha sido operada de un cáncer mamario. Con este acontecimiento, el personaje se da cuenta de la soledad en la cual se encuentra, de la proximidad de la muerte y de la imposibilidad de configurar su vida hacia la trascendencia, todo lo cual lo lleva a reflexionar en torno a su ser:

soy un hombre pequeño y tímido, incambiable [...] El hombrecito que disgusta en la medida en que impone lástima, hombrecito confundido en la legión de hombrecitos a los que fue prometido el reino de los cielos [...] El hombrecito y sus malentendidos, en definitiva, como para todo el mundo [...] Tal vez los huesos lo sepan y [...] cuando vislumbramos que sólo la propia salvación puede ser un imperativo moral; cuando logramos respirar por un impensado resquicio el aire natal que vibra y llama al otro lado del muro, imaginar el júbilo, desprecio y la soltura, tal vez entonces nos pese [...] la convicción de que todo malentendido es soportable hasta la muerte, menos el que lleguemos a descubrir fuera de nuestras circunstancias personales, fuera de las responsabilidades que podemos rechazar [...]. (Onetti, 1968: 53-4).

17 "Inclusión de una historia en el interior de otra [...] La primera narración no es tan sólo un pretexto para introducir la segunda, sino que las dos se otorgan valor recíprocamente..." (Bourneuf, 1975: 86-87).

18 Es innecesario si se recuerda que para el personaje, no existe la salvación tal como el cristianismo la promulga, sino sólo en el sentido de escapar de la sensación de futilidad de la vida. 
Es entonces cuando Brausen comienza a obsesionarse con el argumento ficticio desarrollado en Santa María, sintiendo que los personajes ahí presentes son su único medio de salvación a una vida empequeñecida por el ascetismo innecesario ${ }^{18}$. Desarrolla un protagonista llamado Dr. Díaz Grey, que según se entiende es una versión joven de él mismo y a quien se le presenta en su consultorio la deslumbrante Elena Salas, reminiscencia del personaje mítico, Elena de Troya. Desde luego, la co-protagonista de la historia de Brausen encierra en sí los atributos del mítico personaje, representando así el deseo y su capacidad de cegar la razón a tal punto, que llevaría a la destrucción de una fortaleza como lo era Troya. Entonces, siguiendo con la lógica de la narración encuadernada, es precisamente cuando Elena entra en la vida de Díaz Grey y por consecuencia en la de Brausen, cuando este último se atreve a traspasar e investigar la casa de su vecina Queca y comienza a obsesionarse con ella. Al mismo tiempo, el protagonista comienza un proceso de separación de su mujer, con la cual siente que ha perdido toda conexión.

Mientras Gertrudis se mantiene fuera de la ciudad, Brausen vierte toda su atención hacia la vida de Queca, quien se representa como una mujer deslenguada, audaz, volcada a los placeres de la vida y rodeada de hombres decadentes. Al mismo tiempo, intenta configurar al marido perfecto de Elena Salas, todo lo cual ocurre mientras se mantiene recostado en su cama. Luego, el día que Gertrudis anuncia su regreso a Buenos Aires, Brausen decide visitar a Queca bajo el nombre de Arce y seducirla mintiendo descaradamente. Después del encuentro, Brausen comienza a internarse cada vez más en el personaje de Arce y en la vida de los actores de Santa María, desprendiéndose lentamente de todas aquellas circunstancias que lo atenían a su identidad primera: Gertrudis, su trabajo y su identidad. Así, a cada desprendimiento en el mundo moral y sacralizado de Brausen, le corresponde un avance hacia el mundo de inmoralidad e indiferencia representado por Díaz Grey y Arce. Se configura luego una circularidad en la cual un desprendimiento en el mundo real, implica degradación en la vida simulada e imaginaria, para que entonces esta degradación, la cual otorga sensación de bienestar al personaje ${ }^{19}$, se manifieste como un nuevo desprendimiento en el primer

19 Ejemplo de este sentimiento es la alegría que le produce a Arce ser golpeado por Ernesto, "estuve después sonriendo, en abandono, con el sombrero en la mano, como un mendigo en un portal, sonriendo mientras sentía que lo más importante estaba a salvo si me seguía llamando Arce" (Onetti, 1968: 99). 
mundo. Finalmente, Brausen logra desprenderse de todas aquellas cosas que lo retenían a su identidad y descubre que "había desaparecido el día impreciso en que se concluyó mi amor por Gertrudis; subsistía en la doble vida secreta de Arce y del médico de provincias" (Onetti, 1968: 131). Se desprende así de este hombre asceta hecho de negativas, despojándose de cualquier vestigio de fe que pudiese haber tenido "el hombre con fe supone haber descubierto el sentido de la vida, haberlo obedecido. Pero para esta pequeña vida que empieza o para todas las anteriores si tuviera que empezar de nuevo, no conozco nada que me sirva, no veo posibilidad de fe" (Onetti, 1968: 174).

Comienza entonces la segunda vida del protagonista, una en la cual se regocija tras haber sido golpeado brutalmente por Ernesto, a la vez que descubre el placer en someter y golpear hasta la inconsciencia a Queca, deseando a cada instante poder concretar su deseo de matarla, pues "todo había sido organizado para que yo la matara; examiné mi júbilo, el vigor que casi me hacía sonreír" (Onetti, 1968: 159). Paralelamente, Díaz Grey se va perdiendo cada vez más en las historias de Elena -quien lo guía en una búsqueda absurda del inglés Oscar Owen- de la cual quiere escapar pero no puede, pues se siente absorbido por los designios de esta mujer. Comprendemos entonces que la degradación del personaje es producto de la pérdida de fe y consiguiente desacralización del mundo, todo lo cual le otorga a este último una libertad desencadenada y sin rumbo, la cual radica en el nuevo estado de inmoralidad. Tal como dice Roberto Pinheiro en su estudio sobre Juntacadáveres "La libertad radical implícita en la inmoralidad descubre el absurdo como la falta total de reglas y coherencias. La posibilidad de una libertad sin sentido aparece en la obra de Onetti a través del retrato del indiferente moral, del hombre sin fe ni interés en su destino" (Pinheiro, 2006: 71). El protagonista se descubre dueño de una libertad radical, pues aquello que lo oprimía ha desaparecido y ahora puede sumergirse en los placeres individuales, alejados de la responsabilidad hacia el otro, "esto era lo que yo buscaba desde el principio, desde la muerte del hombre que vivó con Gertrudis, ser libre, ser irresponsable ante los demás, conquistarme sin esfuerzo en una verdadera soledad" (Onetti, 1968: 276). Con estas últimas palabras de Brausen - Arce, se configura un sujeto nihilista, indiferente, degradado e inmoral, a partir de la desacralización e industrialización de un mundo que objetiviza y enajena. 
A partir de lo anterior puede articularse lo que desde el punto de vista hermenéutico se denomina la matriz de sentido, la cual se abordará de la siguiente manera: el hombre de la contemporaneidad, situándose en la perspectiva de un mundo desacralizado, toma conciencia del sinsentido de la vida y recurre al espacio de la ficción, como aquello que intentaría reemplazar la intolerable realidad de un mundo que oprime. Es decir, ante una exterioridad que no le otorga respuestas a la pregunta por el sentido de la vida, el sujeto de la vida breve se vuelca hacia la propia interioridad (representada por la ficción) para poder inventarse, mas, tan sólo se encuentra con un sentimiento de desesperación por la pérdida de trascendencia. El ser humano descubre entonces que su vida se resume en acciones que lo construyen, pero que no le otorgan necesariamente una explicación a su condición de ser arrojado a la muerte $^{20}$. Se descubre desde luego como un ser caído, al que no le queda más remedio que precipitarse a su propia destrucción, a través de la aceptación de su inmoralidad como intrínseca a su constitución psíquica.

Tras el análisis recién efectuado, fue posible tanto ampliar los horizontes ${ }^{21}$, como establecer un macrotexto, el cual nos dispondremos describir a continuación, no sin antes aludir a la cancelación, producida en este nivel, del referente externo y su sustitución por un sistema de comunicación abstracto hecho de lenguaje real. Ha entrado en vigencia la regla F, la cual "impone a todos los participantes en la comunicación estético-verbal la restricción de no admitir los objetos comunicados como interpretables en términos referenciales puros o confrontables con criterios verificadores" (Cuesta Abad, 1991: 218). En otras palabras, se produce una ficcionalización producto de una analogía, lo cual nos introduce en el círculo artístico ${ }^{22}$, en el cual corresponde establecer el punto de hablada y las características del emisor, entre otras cosas, para así perfilar el acto de habla imaginario en el interior del texto.

20 Se observa en la matriz de sentido una estrecha relación con el existencialismo de Sartre, quien dice en su célebre frase "existir es ser para la nada", correlato manifiesto de la frase de Heidegger: "existir es ser para la muerte".

21 Según Schökel (1994) "el horizonte es creciente, se ensancha con cada nueva experiencia y conocimiento." (74). Es decir, cada nuevo conocimiento adquirido se incorpora a los ya establecidos para ampliar así nuestros horizontes. Esto, claro, sin olvidar la regla de la congruencia.

22 Para la estética de la recepción, el círculo artístico "se refiere al texto creado por el autor" (Iser, 1987: 215), en contraposición con el círculo estético, el cual corresponde a "la concretización llevada a cabo por el lector". (215). De esto se desprende que el texto se sitúa a medio camino entre estos dos círculos, donde "la convergencia de texto y lector dota a la obra literaria de existencia, y esta convergencia nunca puede ser localizada con precisión, sino que debe permanecer virtual, ya que no ha de identificarse ni con la realidad del texto ni con la disposición individual del lector" (215). 
Para poder describir al sujeto de enunciación de esta novela, es preciso recalcar su carácter múltiple, en cuanto dentro del relato subsiste una narración encuadrada dentro de otra, lo cual a su vez diversifica las características del narrador. Comenzando por la primera historia, nos situamos frente a un narrador homodiegético e intradiegético ${ }^{23}$, en otras palabras, es el protagonista, Juan María Brausen, quien cuenta su propia historia, de la cual escuchamos sus constantes pensamientos: "Yo la oía a través de la pared. Imaginé su boca en movimiento frente al hálito de hielo" (Onetti, 1968: 11).

Al presentarse este tipo de narrador, podemos constatar que existe poco distanciamiento entre Brausen y los hechos acontecidos en la novela, lo cual recae en una visión angosta y subjetiva respecto a dichos sucesos, los cuales están siendo canalizados por la perspectiva del personaje principal. Así por ejemplo, cuando Raquel, la hermana menor de Gertrudis, va a visitar a Brausen a su departamento en Buenos Aires, éste la presenta como una "cosa grotesca" de "cara huesuda y pálida", que le produce una "sensación repugnante y enemiga", todo lo cual parece muy extraño considerando que al principio del relato, Raquel era representada como una Gertrudis joven, que aún conservaba su belleza. Entonces, descubrimos que esta fealdad repentina le sobreviene a Raquel debido a su estado de embarazo: "la sensación repugnante y enemiga había estado brotando de la panza que le habían hecho, del feto que crecía anulándola" (Onetti, 1968: 213). Es justamente en este momento cuando notamos una de las incongruencia entre el discurso del narrador y la historia y cómo su peculiar visión de mundo va tiñendo los acontecimientos contados, pues es objetivamente difícil que una mujer se torne de ser bella y grácil a grotesca y repugnante por estar embarazada. Sin embargo, es sólo una opinión y es precisamente esto lo que el texto pretende demostrar; la manera en la cual el mundo se va configurando y constituyendo de forma particular y diferente para cada sujeto. Por lo mismo, el texto presenta un narrador con focalización interna fija, donde éste "no dice sino lo que sabe tal personaje: es el relato con punto de vista" (Genette, 1989: 244).

23 Según Genette (1989) el narrador puede clasificarse respecto a la historia que se cuenta y en relación al discurso de la narración. En el primer caso se habla de narrador homodiegético cuando forma parte de la historia contada, siendo su contrario el narrador heterodiegético. Por otro lado, si el narrador está dentro del universo diegético, entonces se le considera un narrador intradiegético, mientras que si está fuera del mundo narrado entonces se le denomina extradiegético (Cfr. Figuras III). 
Ahora bien, considerando que el enfoque de este narrador protagonista se caracteriza por una repulsión a la vida rutinaria y moralizante debido a la pérdida de sentido, comprendemos entonces el repudio hacia Raquel no como algo físico sino más bien psicológico, en cuanto ha ingresado al mundo rutinario y ha abandonado otro lleno de sensualidad.

Está loca, no tiene derecho a esto, a convertirse en una ruina grotesca, a deformar a la Raquel en que yo pensaba cuando estaba triste. Tengo que arrastrarle el sombrero, tengo que verle la cabeza redonda y el pelo revuelto, tratar de ver la cara de Raquel antes que sea imposible. Porque así como el traje recto y flojo es el uniforme de todas las inminentes madres del mundo, el pequeño sombrero sin adorno, ceñido como un casco, proclama la resolución de la pureza, el desprecio por las posibilidades sensuales de la vida, su adhesión al deber y a la soberbia estupidez. (Onetti, 1968: 215).

A los ojos de Brausen, Raquel, al quedar embarazada, pierde la posibilidad de acceder a esta preciada libertad radical, causada por el desasimiento del mundo opresor de las rutinas y los pequeños aconteceres que no guían a ningún destino prediseñado. Son precisamente estos "ojos" los que configuran esta narración focalizada en todo momento y que nos presentan una realidad subjetivizada, en la cual sólo a ratos podemos acceder a otra subjetividad debido a la utilización del estilo directo o discurso restituido ${ }^{24}$. Sin embargo los comentarios efectuados por otros personajes se presentan tan precarios, inconexos y faltos de profundidad, que es difícil salirse de este mundo subjetivizado por Brausen y acceder a una mirada diferente del mundo y de los personajes que ahí actúan. Es decir, como las intervenciones de estos últimos a través de un discurso restituido se presentan de manera fragmentaria y seleccionadas por el narrador, más que darnos una visión de ellos y su forma de pensar, refuerzan la mirada del protagonista. Del mismo modo, el sujeto de la enunciación va relatando sólo aquellos momentos que él considera importantes, saltando a veces de un suceso a otro sin previo aviso, donde de pronto nos encontramos en un bar cuando recién el personaje estaba en su casa. En consecuencia, no llegamos a conocer a

24 El discurso restituido es aquel en el cual "el narrador finge ceder literalmente la palabra a su personaje: “Dije a mi madre (o pensé): tengo que casarme con Albertine"”' (Genette, 1989: 229-230). 
Gertrudis, a Queca, a Stein y muchos otros, si no es a través de la mirada del protagonista, quien los caracteriza crítica y subjetivamente, tal como vimos con la descripción de Raquel. De esta forma, el narrador homo e intradiegético, se convierte en la única puerta de acceso al relato. Así por ejemplo, durante la huida del protagonista con Ernesto, poco sabemos de las razones que él tuvo para asesinarla, pues a Brausen no le interesan, en su mundo lo importante son las razones que él tenía para matarla y es por eso que empatiza con el personaje: “Te lo dije cien veces -contesté- . Quise ayudarte porque me parecía injusto que te pudrieras en la cárcel por una cosa que yo mismo hubiera hecho, que me parecía bien hacer" (Onetti, 1968: 267).

Descrita la figura del narrador de la primera historia, podemos situar el punto de hablada en el momento en que el protagonista se descubre solo y hastiado de una vida que no lo satisface, asunto del cual se da cuenta cuando siente la proximidad de la muerte, situación ilustrada por la operación de cáncer mamario de su esposa Gertrudis. Este punto de hablada es compartido por la otra narración, en la cual Brausen funciona como autor intradiegético de una obra metadiegética, dentro de la cual actúa como un narrador omnisciente con focalización cero: "Díaz Grey casi se interesó por el prólogo; miró las pupilas dilatadas de la mujer, supuso que estaba mintiendo, que había venido exclusivamente para mentir" (Onetti, 1968: 38). De esta forma, Brausen se transforma en el coordinador y constructor de los personajes de Santa María; de los cuales sabe lo que piensan y sienten. Ahora bien, es de esperar que al tratarse de un narrador omnisciente, éste ejerza un papel más dominante respecto a la historia y el mundo narrado, sin embargo el narrador no se hace muy presente en la historia a través de un discurso narrativizado, más bien utiliza el discurso restituido y el transpuesto (o estilo indirecto), a la vez que se descubren monólogos interiores o discursos inmediatos marcados por comillas: "Usted me vio desnuda, medicucho; usted debió tocarme para evitar que ahora yo sea una madre para usted" (Onetti, 1968: 94). Esta manera de narrar le da más autonomía a los personajes metadiegéticos, a quienes conocemos ya no a través de la visión limitada de un personaje, sino a través de sus propias palabras y pensamientos ${ }^{25}$.

25 Esto ocurre sobre todo debido al discurso inmediato, en el cual "el narrador se desdibuja y el personaje lo substituye". (Genette, 1989: 231). 
Pero ¿por qué tanta autonomía respecto a estos personajes? ¿Por qué Brausen les cede la preciada oportunidad de expresar su interioridad a expensas de su participación en el relato? Si consideramos lo analizado con anterioridad en el círculo histórico y retomamos la idea de una realidad que oprime al personaje con su rutina sin sentido, podemos entender que Brausen, a través de esta metadiégesis, está intentando objetivizarse a través de la alienación para poder vivir otra vida y así evadir este mundo opresor. Por esto le otorga mayor autonomía a sus personajes; Brausen está tratando de conocerse a sí mismo a través de la objetivización para lograr luego modificarse, pues descubre que para lograr entender su interioridad, debe pensar en ella como se piensa en el comportamiento de otra persona de la que se es testigo ${ }^{26}$. Descubrimos entonces cómo estos personajes -sobre todo Díaz Grey- representan los conflictos y deseos de liberación de un Brausen oprimido por una vida de gran ciudad que finalmente lo enajena. Entendemos ahora por qué a cada cambio en el metarrelato acontece un cambio en el relato primero, constituyéndose la narración en segundo nivel como aquella que explica la radical transformación de Brausen hacia Arce.

No obstante la autonomía que pueden adquirir los personajes mediante los discursos restituidos e inmediatos, es Brausen - narrador quien controla este discurso y las palabras de los personajes, o bien es esto lo que ocurre hasta el capítulo ocho de la segunda parte. En dicho apartado, Brausen decide ponerle fin al mundo ficticio, excluyendo de ello a Díaz Grey. Sin embargo, algunos capítulos más adelante sin explicación alguna, aparecen nuevamente los personajes del metarrelato, como si en una emancipación hubiesen decidido continuar con vida. Tanto así, que el último capítulo del texto es narrado por Díaz Grey en primera persona y en presente, creándose una transgresión llamada metalepsis narrativa ${ }^{27}$, en donde personajes metadiegéticos son atraídos al universo diegético. Se rompe entonces la frontera entre los dos mundos, descubriéndose que así como Brausen crea un relato que se autonomiza y se estructura como realidad, también la realidad que Brausen conoce, no es más que un relato creado por su subjetividad, y entonces nos damos cuenta de que si queremos, "se puede vivir muchas veces, muchas vidas

26 Cfr. Bourneuf, La novela (1975).

27 "toda intrusión del narrador o del narratario extradiegético en el universo diegético (o de personajes diegéticos en un universo metadiegético, etc.) o, inversamente [...], produce un efecto extravagante ora gracioso [...] ora fantástico" (Genette, 1989: 290). 
más o menos largas" (Onetti, 1968: 173). Pues al ser la individualidad un constructo lingüístico, al igual que el mundo que el sujeto habita, no hay problema en rearticular este lenguaje cuantas veces se desee. Además, se sustenta la idea de que estamos viviendo en una ilusión de fe, en un relato configurado por la religión cristiana que nos confiere una falsa sensación de seguridad y comprensión del mundo: “Cualquier pasión o fe sirven de felicidad en la medida en que son capaces de distraernos, en la medida de la inconsciencia que pueden darnos" (Onetti, 1968: 174). Cuando finalmente, lo único verdadero es nuestra propia interioridad, pues sólo a ella tenemos acceso. Por eso, es esta realidad y no otra, la que sobrevive al finalizar la novela.

Tras este análisis de la figura del narrador, hemos descrito el macrotexto y delineado el acto de habla imaginario, todo lo cual se lleva a cabo en el plano ficcional del modelo hermenéutico, en el cual los referentes se han mantenido cerrados. Mas, ahora corresponde entrar en el plano fictivo de la novela, donde validamos una existencia ónticamente homogénea entre emisor, receptor y texto, a la vez que los referentes se vuelven a abrir, pero no hacia una realidad externa, sino como un acto de habla imaginario. Este traspaso de lo ficcional a lo fictivo es producto de una analogía que posibilita la aparición de entes imaginarios como si fueran del mundo real, constituyéndose así los mundos posibles, denominados así por tener referentes imaginarios. En este movimiento que desplaza el eje de control desde la referencia externa hacia la interna, el texto se monumentaliza, entrando finalmente al círculo estético, en el cual corresponde describir cómo funciona la estructura de conjunto referencial (E.C.R.) presentada en la obra, para que se produzca entonces la ya graficada fusión de horizontes.

Los diseños referenciales que luego constituyen los universos fictivos de la obras literarias, se conforman semióticamente sobre una "trama de ejes representativos de las distintas estructuras del mundo..." (Cuesta Abad, 1991: 208), ejes denominados mundo objetivo, social y subjetivo $^{28}$. Con respecto a la obra analizada, es de suma importancia la

28 El mundo objetivo se subdivide en universo epistémico y doxástico (creencias y opiniones); el social en universo deóntico y axiológico; mientras que el subjetivo en autopresentación y heteropresentación. (Cfr. Cuesta Abad. Teoría hermenéutica y literatura (1991). Es importante establecer que el mundo social, en el cual se analizan "las subestructuras expresivas y pragmáticonormativas del lenguaje y la comunicación literaria, que modifican y reordenan, merced a la función estética, la producción e interpretación de los mensajes poéticos" (209), ya ha sido parcialmente analizado al presentarse la figura del narrador. 
expansión y modelización semántica del mundo objetivo, es decir "las construcciones estéticas [...] que, apoyándose en unos y otros sectores cognitivamente modelizados del mundo físico-objetivo, amplían el alcance de sus contenidos ontológicos [...] sobredimensionando sus posibilidades de remisión referencial" (Cuesta Abad, 1991: 209). De este modo, son interesantes las manipulaciones realizadas en el paradigma de modalidades del mundo axiológico, en cuanto los conceptos "bien" y "mal", cristianamente entendidos, sufren una inversión, a la cual se le suma una actitud de indiferencia ante cualquier acto moralmente evaluable. Así, el protagonista de la obra sufre una involución moral, en la cual pasa de ser un sujeto asceta y preocupado de su mujer (Brausen), a transformarse en un individuo indiferente ante los demás, el cual además disfruta golpeando a su amante y contemplando su dinero (Arce). Esta transformación en las modalidades del mundo axiológico responde, como ya se había enunciado, a una inseguridad ontológica producto de la desacralización del mundo. Así, el emisor, al perder la noción de Dios como unificador, regidor y fin último de la existencia humana, descubre el mundo como una interrogante que analiza en busca de sentido. Mas este sujeto no logra configurar sus experiencias como un conjunto direccionado, comprendiendo en su desesperación, que su vida no es más que un continuo de malentendidos. Precisamente esto último produce la inversión en el mundo axiológico, pues de nada sirve una moral cristiana si la vida no trasciende más allá de lo corpóreo.

Asimismo, la falta de una visión divina-omnisciente del mundo, es también responsable de las alteraciones producidas en las modalidades de dicho mundo. Éste se presenta la mayor parte de la obra como homogéneo, en cuanto es enteramente natural, hasta que en el último capítulo acontece un hecho sobrenatural: los personajes de un relato metadiegético surgen en la diégesis. Esta expansión semántica del mundo objetivo, como ya vimos, resulta de un desdoblamiento interior del emisor. El personaje se duplica y así el espacio se abre como un abismo en el que se multiplican las imágenes. Multiplicidad que muestra sus atisbos al principio de la obra, para establecerse constitutivamente al finalizar ésta. Es la manifestación del proceso por el cual un mundo en principio unitario, debido a un plan divino englobador de la sociedad, comienza a fracturarse lentamente hasta alcanzar una binariedad impuesta por el propio emisor, sujeto incapaz de conferirle al mundo la unidad perdida. 
Lo anterior nos introduce instantáneamente en el tercer dominio de referencia; el mundo subjetivo, del cual se analizan "los complejos de representación dramatúrgica [...] por los que se pretende objetivar comunicativamente los niveles psíquicos de la emotividad personalidad subjetiva" (Cuesta Abad, 1991: 209). Para conformarse la autopresentación del personaje, es necesaria la conexión de este último con su mundo subjetivo, entendiendo éste como los deseos, opiniones y sentimientos del emisor, los cuales no pueden ser correlacionados con ningún estado de cosas dado en el mundo objetivo, pero que igualmente no escapa a una comprobación objetiva a través del análisis del discurso ${ }^{29}$. A raíz de lo anterior, se introduce en la obra una distinción entre mundo interno y mundo externo, implantándose entonces "el problema de la correspondencia entre los estados subjetivos de hablante y la conformación expresiva con que éste pretende comunicar tales estados" (Cuesta Abad, 1991: 221). Con respecto a lo enunciado, describimos la peculiar forma expresiva de Brausen, la cual a su vez desemboca en la formulación del mundo externo de manera parcelada debido a su incapacidad de aprehenderlo sin acudir al mundo interno. El relato se configura entonces como la autopresentación de Juan María Brausen, siendo el espacio predominante del relato el mundo subjetivo, lo cual conlleva a las ya descritas alteraciones en el mundo objetivo, para así enfocar la atención en esta subjetivización del entorno.

\section{Conclusiones}

En suma, considerando lo hasta ahora analizado en los círculos histórico, artístico y estético, y así apuntando a la esperada fusión de horizontes, podemos dilucidar la existencia de un mundo recientemente quebrantado, debido a la pérdida de creencia en un destino trazado de antemano por un Dios omnisciente capaz de otorgarle trascendencia al individuo. Se constituye entonces un mundo bifronte, dividido en un submundo real - objetivo y otro subjetivo. El primero está constituido por el espacio cotidiano de las grandes ciudades contemporáneas, donde se sustituye la moral cristiana por una de mercado que enajena y doblega la voluntad del individuo. Además, este último, al encontrarse de pronto inserto en un mundo desacralizado, se le presenta como un interrogante que intenta comprender en vano desde su mirada parcelada

29 Análisis ya efectuado en este trabajo al sondear la congruencia entre el discurso del narrador y la historia acontecida. 
de la realidad. Entonces, el sujeto oprimido intenta evadirse a partir del volcamiento de su mirada hacia la propia interioridad. De este modo el mundo se bifurca por una imposición de este último, quien intenta sustentarse ontológicamente ya no en una exterioridad (Dios/Iglesia), sino en un miramiento hacia su propio inconsciente.

Sin embargo, al ocurrir este cambio de mirada, el personaje en vez de conseguir un soporte a su inseguridad ontológica, descubre que la realidad como tal no puede ser aprehendida si no es a través del prisma de la propia interioridad -única realidad a la cual tenemos acceso-, conformándose así un realismo subjetivo. De esta forma, el protagonista sale de un mundo opresor para entrar en la relatividad e inseguridad de un subjetivismo constitucional, que en vez de otorgarle respuestas a su angustia ontológica, más bien le confiere la visión de un relativismo moral producto de esta subjetividad del entorno y del descubrimiento de la constitución a-trascendente del sujeto. La vida eterna se desdibuja como fundamento del ser humano y a ella le sobreviene la vida breve, aquella sustentada por la corporeidad del sujeto y por la verbalización de su interioridad, lo cual le confiere la posibilidad de reinventarse inescrupulosamente cuantas veces lo desee.

\section{Bibliografía}

Bourneuf, R. y Ouellet, R. (1975). La novela. Barcelona: Ariel.

Cuesta Abad J. M. (1991). Teoría hermenéutica y literatura. Madrid: Visor.

Gadamer, H. (1977). Verdad y método (4ta. Edición). Salamanca: Ediciones Sígueme.

Genette, G. (1989). Discurso del relato en Figuras III. Barcelona: Lumen.

Iser, W. (1987). El proceso de lectura: enfoque fenomenológico en Estética de la recepción. Madrid: Arco.

Nuevo Testamento (1989). Edición pastoral (15ta. Edición). Madrid: Editorial Verbo Divino.

Onetti, J.C. (1968). La vida breve. Buenos Aires: Editorial Sudamericana.

Pinheiro Machado, R. (2006). "Juntacadáveres: Absurdo y abyección en la obra de Juan Carlos Onetti". Taller de Letras 38 (2). 55-73.

Schökel, L. A. y Bravo, J. M. (1994). Apuntes de hermenéutica. Madrid: Trotta. 
